\title{
Multimodalidade e análise linguística: explorando o gênero anúncio publicitário
}

\author{
Raimundo Expedito dos Santos Sousa \\ Universidade Federal de Minas Gerais \\ Vanessa Arlésia de Souza Ferretti-Soares \\ Universidade Federal de Santa Catarina
}

Ederson Luís Silveira

Universidade Federal de Santa Catarina

\begin{abstract}
Resumo
O presente trabalho de investigação interpretativa-qualitativa visa lançar luzes ao (des) aparecimento de textos multimodais na escola na contemporaneidade. Um dos objetivos centrais da escola é possibilitar que os estudantes participem de várias práticas sociais nas quais a leitura e a escrita se faz presente direta ou indiretamente. Assim, após situar historicamente a constituição dos objetos de ensino na disciplina de língua portuguesa e de problematizações acerca da multimodalidade, será apresentado um exemplo de análise do discurso publicitário em que podem ser apreendidas as instâncias multimodais de constituição do texto enquanto objeto de reflexões, especificamente de análise linguística. Isso faz pensar acerca do papel da escola frente a essa complexidade de espaços e temporalidades que o advento das novas tecnologias fez vigorar e cujas discussões não podem ser ignoradas.

Palavras-chave: texto multimodal, ensino, publicidade.
\end{abstract}

\begin{abstract}
:
The present paper, based on qualitative interpretative research, aims to shed some light on the (dis)appearance of multimodal texts in school in contemporary times. One of the central objectives of the school is to enable students to participate in various social practices in which reading and writing are directly or indirectly present. We will historically situate the constitution of the objects of teaching in the subject of Portuguese language and the problematizations concerning multimodality. Then, we will present an example of an analysis of advertising discourse in which the instances of multimodal text can be seen as an object of reflection, specifically of linguistic analysis. This makes us think about the role of the school facing this complexity of spaces and temporalities that the advent of new technologies has invigorated and whose discussions cannot be ignored.
\end{abstract}

Keywords: multimodal text, teaching, advertising. 


\title{
INTRODUÇÃO
}

Sob os efeitos, principalmente, do desenvolvimento tecnológico, o mundo contemporâneo tem se caracterizado por profundas recodificações e reestruturações que contribuem para o engendramento de um novo ordenamento socioeconômico e cultural no qual o progresso tecnológico implica transformações em diversos âmbitos da atividade humana. Neste contexto, a escola não passa ilesa a estas transformações. Nela, no entanto, tradicionalmente, o texto aparece como pretexto para ilustração de regras gramaticais, tendo seus sentidos frequentemente esvaziados. Neste contexto, então, o estudo dos multiletramentos emerge a partir da possibilidade de trazer à luz outros enfoques para além das vestes tradicionais com que se veste o ensino, como podemos perceber através das palavras de Silveira (2014).

\begin{abstract}
Nas aulas de língua Portuguesa, o texto é frequentemente usado como pretexto em livros didáticos para ilustrar regras gramaticais, sem que se propicie o debate sobre o objeto em questão, que passa a ter seus sentidos esvaziados na prática de um ensino mecânico que se propõe apenas a classificar e categorizar nomenclaturas de classes presentes em seu interior. Uma sugestão pertinente para que possamos pensar um ensino de Língua Portuguesa voltado para a reflexão sobre a língua, enquanto organismo mutável, utilizável pelos usuários no universo das práticas de linguagem, é justamente a adoção de práticas que atentem para este contexto social de significação em que os textos estão inseridos. $O$ estudo dos (multi)letramentos aponta para renovações metodológicas que compreendam a contemplação da complexidade de necessidades que envolvem os processos de interação. Como na atualidade há uma grande necessidade de utilização de textos de acordo com as necessidades dos usuários da língua nos ambientes sociocomunicativos, é preciso que ensino perceba e propicie a reflexão sobre essa dinamicidade. (SILVEIRA, 2014, p. 19)
\end{abstract}

Levando em consideração a inserção cada vez mais abrangente em contextos de uso da língua de instâncias sociocomunicativas e os reflexos dessa multiplicidade de sujeitos inseridos em práticas de linguagem na escola, a necessidade de novos paradigmas no contexto escolar emerge com fim de, por um lado, possibilitar o diálogo com essas transformações sociais e, por outro, preparar os alunos para transitar nesse meio, reconhecendo-se como seres que fazem parte desse contexto sócio-histórico, e se posicionando diante dessas transformações de modo crítico, participante, como propõe Freire (1967).

Para tanto, é preciso que a escola, uma das principais agências de formação para grande parte das camadas da sociedade, altere sua estrutura administrativo-pedagógica e 
priorize práticas educacionais que coadunem com uma nova configuração cultural balizada por uma multiplicidade de linguagens, na qual a linguagem voco-visual, por exemplo, tende a se fazer cada vez mais presente (ROJO, 2009).

Se, conforme Freire (1997), a função primeira da escola é favorecer o desenvolvimento de saberes e competências necessárias para a formação de sujeitos críticos e participativos, capazes da agir sobre o mundo em que se inserem, o ensino de língua(gem) deve ser pensado em uma dimensão social, privilegiando as diferentes formas de linguagem de que lançamos mão em nossas interações diárias, dentre o que está a linguagem imagética, a multimodalidade, aspecto que reconfigura, inclusive, a noção do que seja o próprio "texto". Longe de ser um amontoado de frases, centrado especificamente na linguagem verbal, o texto deve ser então entendido como um todo constituído de sentido $(\mathrm{KOCH}, 2003)$, o que implica considerar como partícipe dessa constituição a dimensão voco-visual.

Nesse sentido, o presente artigo tem por objetivo apresentar algumas implicações para o ensino de língua materna, sobretudo em atividades de leitura e análise linguística, do trabalho com gêneros em que a multimodalidade é um aspecto saliente, como é o caso do anúncio publicitário. Para tanto, apresentamos a seguir apontamentos sobre a própria constituição dos objetivos da disciplina de língua portuguesa, a demanda pela transformação desses objetivos e das próprias concepções de linguagem que pautaram essas transformações. Em seguida, explicamos o que vem a ser a multimodalidade, localizando-a no contexto de consideração das múltiplas semioses em que a linguagem pode se manifestar no cotidiano dos usos da língua e, por fim, analisamos um anúncio publicitário, de modo a explicitar a relação entre uma análise multimodal com as diretrizes de um ensino de língua pautado numa perspectiva sociointeracionista $(\mathrm{KOCH}, 2003)$.

\section{DAS TRANSFORMAÇÕES NO ENSINO DE LÍNGUA MATERNA: A CONSTITUIÇÃO DOS OBJETOS DE ENSINO E APRENDIZAGEM}

Desde os últimos decênios do século $\mathrm{XX}$, o ensino de língua portuguesa - tanto no âmbito da pesquisa quanto de diretrizes oficiais - vem sendo discutido de forma mais sistemática, de modo que se aponta para as limitações do ensino pautado na gramática normativa/tradicional que preponderou nas aulas de língua portuguesa até 
alguns anos atrás. Limitações advindas tanto de problemas da própria gramática quanto dos objetivos que se buscavam alcançar por meio do seu ensino, como é o caso de vinculá-la ao desenvolvimento da capacidade de leitura e produção textual (BRITO, 1997).

Essas limitações tornaram-se ainda mais salientes quando, na década de 50, houve o ingresso massivo de camadas populares aos bancos escolares. Nesse contexto, como aponta Soares (apud BRITTO, 1997), o fracasso escolar tornou-se algo visível, massivo. Segundo a pesquisadora, motivado pelo fato de que

[...] o aluno que vem das classes dominadas encontra na escola padrões culturais que não são os seus e que são apresentados como 'certos', enquanto os seus próprios padrões são ou ignorados como inexistentes, ou desprezados como "errados" (SOARES apud BRITTO, 1997, p. 98).

A despeito dessa disparidade de capital cultural, em 1976, com a obrigatoriedade da prova de redação nos vestibulares, começou a ganhar corpo a ideia de que o conhecimento de gramática não garantia ao aluno, de qualquer camada social, uma redação adequada nem o domínio da técnica da boa (sic) comunicação (BRITTO, 1997). É no final dessa década, então, e durante os anos 80, que se estabeleceria o que ficou conhecido como "a nova crítica do ensino de português". Nesse momento surgem diferentes concepções de língua, de sujeito e de objetivos da escola. No período, segundo Britto (1997), houve um crescente empenho pela aplicação de modelos teóricos ao estudo de língua. Além disso, segundo o autor mencionado, houve significativa expansão na oferta de cursos de extensão para professores da rede básica e de grupos de pesquisa que tinham como base essa nova perspectiva de ensino, preocupada, sobretudo, com a promoção da leitura.

Nesse contexto, conforme aponta Britto (1997), o objetivo maior é reverter o entendimento do papel da escola como se esta tivesse a finalidade de mero local em que se dá a apresentação de conteúdos específicos. Isso se faz emergente porque a posição anterior pressupõe que os alunos nada sabem e que adquirir saber significaria tomar conhecimento dos conteúdos gramaticais apresentados na escola e dominar a técnica da redação para a comunicação efetiva. Dessa forma, significa também pressupor que o processo de ensino e aprendizagem de língua é algo neutro, tecnicista quando, na verdade, conforme Geraldi, 
[...] qualquer proposta metodológica é a articulação de uma concepção de mundo e de educação - e por isso uma concepção de ato político - e uma concepção epistemológica do objeto de reflexão - no nosso caso, a linguagem - com as atividades desenvolvidas em sala de aula. (GERALDI apud BRITTO, 1997, p. 105)

Portanto, a neutralidade não existe e tomar consciência disso implica perguntar quem são os agentes do conhecimento, em que situação histórica se inserem e quais seus interesses políticos reais (BRITTO, 1997). Implica, também, perguntar que sociedade é essa e quais gêneros são por ela mobilizados, como se articulam em termos de linguagem e qual é a relação dessa articulação com os efeitos que provocam nas práticas sociais de que os alunos já participam e/ou participarão.

Nesse momento, a crítica ao ensino de gramática da maneira como o faziam era cara às reflexões sobre a disciplina de LP, já que, segundo Britto (1997), até a prática de produção de texto acontecia apenas para o ensino da norma, a norma de textos especificamente verbais, com destaque para a correção dos erros limitados de ortografia, concordância e regência. Nesse contexto, a multimodalidade não seria nem mesmo pauta de estudo, pois a noção de texto estava centrada substancialmente na linguagem verbal.

De qualquer forma, sair do ensino de conceitos gramaticais para o ensino de língua como algo operacional e reflexivo tem significado um grande avanço para a área, uma vez que esse entendimento parte da reflexão sobre o modo como o sujeito constrói conhecimento sobre a língua, havendo um deslocamento radical dos papéis de aluno e professor. Esses deixam de significar funções que se exercem no interior da escola e passam à condição plena de interlocutores. Além disso, privilegia-se o uso efetivo da língua, já que só se aprende uma língua na medida em que, operando com ela, comparam-se expressões, transformando-as, experimentando novos modos de construção. A língua é, então, resultado deste processo ininterrupto, sobre o qual incidem as avaliações, valorações, disputas etc. (BRITTO, 1997).

É sob tais perspectivas, que Geraldi (1997) propõe que a prática pedagógica se baseie no tripé: leitura, produção textual e análise linguística; entendendo a produção textual como o momento em que o sujeito compromete-se com sua palavra e faz uma articulação individual com sua formação discursiva (GERALDI, 1997). 
Já a prática de leitura de textos se faz ao mesmo tempo das atividades de produção, sendo a contraface imediata dessas. Assim como escrevemos para que nos leiam, lemos porque queremos saber o que o outro tem a dizer (GERALDI, 1997). Por fim, a prática de análise linguística se caracteriza por um debruçar-se sobre os modos de ser da linguagem e ocorre no interior das práticas de leitura e produção.

As questões ressaltadas pela crítica da década de 80, como pontuamos acima, foram ainda acrescidas de pontos teóricos e metodológicos importantes nos anos 90 e 2000. Sobretudo, pela difusão do conceito de gêneros discursivos de Bakhtin (2003). Todas essas questões vieram influenciar a escritura dos parâmetros oficiais para a disciplina - PCNLP (BRASIL, 1998). Nesse sentido, atualmente, o trabalho com os gêneros discursivos passa a fazer parte da esfera escolar, buscando dar conta das inúmeras críticas de outrora. Ao estar relacionado com os gêneros discursivos e as linguagens em múltiplas semioses, nesse contexto, o multimodal aparece como algo significativo no sentido de que sendo os textos atuais, em grande recorrência quantitativa, multimodais, cabe à escola trazê-los para as atividades de leitura, análise e produção textual. Mas o que seria a multimodalidade e qual sua relação com a análise linguística? É sobre isso que trata a próxima seção.

\section{MULTIMODALIDADE}

Kress \& Van Leeuwen (2001) postulam que nos textos ocorre uma reciprocidade de diferentes formas de construção de significados, em que a materialidade verbal se correlaciona com a visual, a sonora, dentre outras. Destarte, o processo de significação se dá de forma multimodal. Mas o que vem a ser multimodalidade?

Relativamente novo, o conceito de multimodalidade nos gêneros discursivos surgiu, no campo da linguística há cerca de duas décadas. A noção de multimodalidade foi introduzida por Kress \& van Leeuwen (1996) no campo epistemológico da Semiótica Social, com vistas à compreensão de todos os modos de representação contidos no texto: "Visual structures realize meanings as linguistic structures do also 
and thereby point to different interpretations of experience and different forms of social interaction" (KRESS \& VAN LEEUWEN, 1996, p.2). ${ }^{1}$

Para a Semiótica Social, semelhantemente às perspectivas de Geraldi e Brito apresentadas anteriormente, a língua não pode ser dissociada do contexto sociocultural em que se inscreve enquanto prática social. Nesse sentido, nenhum código pode ser estudado de forma isolada. Na perspectiva multimodal o sentido advém da relação textual estabelecida entre os diferentes modos utilizados para sua constituição:

\begin{abstract}
In the past, and in many contexts still today, multimodal texts (such as films or newspapers) were organized as hierarchies of specialist modes integrated by an editing process. Moreover, they were produced this way, with different hierarchically organized specialists in charge of the different modes, and an editing process bringing their work together. Today, however, in the age of digitization, the different modes have technically become the same at some level of representation, and they can be operated by one multi-skilled person, using one interface, one mode of physical manipulation, so that he or she can ask at every point: 'Shall I express this with sound or music?' 'Shall I say this visually or verbally?' and so on. (KRESS \& VAN LEEUWEN, 2001, p. 2). ${ }^{2}$
\end{abstract}

Assim, nas mais diversas situações comunicativas, fazemos uso de ao menos dois modos de representação, o verbal e o visual. A multimodalidade constitui-se, portanto, das múltiplas linguagens que utilizamos em práticas sociais interativas:

A spoken text is not just verbal but also visual, combining with 'non-verbal'
modes of communication such as facial expression, gesture, posture and other
forms of self-presentation. A written text, similarly, involves more than
language: it is written on something, on some material (...) and it is written
with something (...); with letters formed in systems influenced by
aesthetic, psychological, pragmatic and other considerations; and with a
layout imposed on the material substance, whether on the page, the

\footnotetext{
1 "Estruturas visuais produzem significados assim como as estruturas linguísticas e, assim, apontam para diferentes interpretações de experiências e diferentes formas de interação social" (KRESS \& VAN LEEUWEN, 1996, p.2, tradução nossa).

2 "No passado, e em muitos contextos ainda hoje, textos multimodais (como filmes ou jornais) foram organizados como hierarquias de modos especializados integrados por um processo de edição. Além disso, eles foram produzidos dessa maneira, com diferentes especialistas hierarquicamente organizados, responsáveis pelos diferentes modos, e um processo de edição que apresentava seu trabalho em conjunto. Hoje em dia, no entanto, na era de digitalização, os diferentes modos têm tecnicamente se tornado o mesmo em algum nível de representação, e podem ser operados por uma pessoa polivalente, utilizando uma interface, um modo de manipulação física, de modo que ele ou ela pode pedir a qualquer momento: 'Devo expressar isso com som ou música?' 'Direi isso visualmente ou verbalmente?' e assim por diante". (KRESS \& VAN LEEUWEN, 2001, p. 2, tradução nossa).
} 
computer screen or a polished brass plaque' (KRESS \& VAN LEEUWEN, 1996, p.39). ${ }^{3}$

Dentre os maiores especialistas brasileiros em multimodalidade, Dionísio (2006) define o conceito como um componente estruturante do discurso que se articula através de mais de uma forma, propiciando uma percepção semiótico-discursiva da linguagem como prática social:

\begin{abstract}
Imagem e palavra mantêm uma relação cada vez mais próxima, cada vez mais integrada. Com o advento das novas tecnologias, com muita facilidade se criam novas imagens, novos layouts, bem como se divulgam tais criações para uma ampla audiência. Todos os recursos utilizados na construção dos gêneros textuais exercem uma função retórica na construção de sentidos dos textos. Cada vez mais se observa a combinação de material visual com a escrita; vivemos, sem dúvida, numa sociedade cada vez mais visual (DIONÍSIO, 2006, p. 32).
\end{abstract}

Em outro trabalho, Dionísio (2005) argumenta que os avanços tecnológicos determinam novas formas de interação que implicam a necessidade de revisão e ampliação das práticas pedagógicas. Nessa mesma perspectiva, Mayer (2001) afirma que os estudantes de língua tendem a aprender mais facilmente por meio de palavras e imagens do que somente por signos verbais, uma vez que palavras e imagens são sistemas diferentes de representação, ou seja, as ilustrações ou a disposição de um texto importam tanto quanto o texto em si. Nesse sentido, como afirma Rojo (2009), a multimodalidade não é apenas a soma de linguagens, mas a interação entre linguagens diferentes em um mesmo texto, de modo que a leitura e análise linguística na sala de aula servem para tornar essa relação inteligível, possibilitam ao aluno a reflexão sobre a linguagem e o mundo.

Descardesi (2002, p.20) complementa que todo texto é multimodal, o que vem ao encontro dos estudos de Kress \& Van Leeuween (2001), para quem as múltiplas linguagens são utilizadas nas práticas sociais de interação, conforme mencionamos anteriormente:

\footnotetext{
3 Um texto falado não é apenas verbal, mas também visual, combinando com os modos de comunicação 'não-verbais', tais como expressão facial, gestos, postura e outras formas de autoapresentação. Um texto escrito, da mesma forma, envolve mais de uma linguagem: está escrito em alguma coisa, em algum material (...) e é escrito com alguma coisa (...); com letras formadas em sistemas influenciados por considerações estéticas, psicológicas, pragmáticas e outros; e com um layout imposto à substância material, quer na página, na tela do computador ou numa placa de latão polido (KRESS \& VAN LEEUWEN, 1996, p.39, tradução nossa).
} 
Em uma página, além do código escrito, outras formas de representação como a diagramação da página (layout), a cor e a qualidade do papel, o formato e a cor (ou cores) das letras, a formatação do parágrafo, etc. interferem na mensagem a ser comunicada. Decorre desse postulado teórico que nenhum sinal ou código pode ser entendido ou estudado com sucesso em isolamento, uma vez que se complementam na composição da mensagem.

Portanto, sob um viés multimodal, as imagens e outros signos, longe de atuarem nos textos como meras ilustrações, são elementos constitutivos fundamentais para sua significação. Ao sinalizar isso, quer-se acentuar que a escola não pode mais continuar apresentando textos nas instâncias de ensino como se estes tivessem que ser reduzidos ao que o autor quis dizer, à intencionalidade do enunciador, sem considerar os aspectos sincréticos de sua produção, porque estes também implicam em efeitos nas instâncias possíveis de interpretações apreendidas nas leituras realizadas. Isso porque, como afirmou Bakhtin (1988), apreender significados é ação ativa, o que implica perceber a presença de réplicas e não de repetições.

A fim de explicitar a relação entre a análise da multimodalidade com as diretrizes de um ensino de língua pautado numa perspectiva sociointeracionista (difundida a partir da década de 80), sobretudo, por meio de atividade de leitura e análise linguística, apresentaremos na próxima seção um anúncio publicitário e o analisaremos apontando para aspectos que propiciam a reflexão sobre a linguagem durante a atividade de leitura.

\section{ANÚNCIO PUBLICITÁRIO, LEITURA E ANÁLISE LINGUÍSTICA}

O anúncio abaixo faz parte de uma campanha publicitária intitulada "Dirija com responsabilidade", realizada pela empresa Fiat, a fim de atingir ao público online e, segundo a empresa, conscientizar os motoristas acerca dos perigos de beber antes de dirigir. O anúncio foi veiculado em plataformas online durante o ano de 2012, local em que o vídeo teve mais de cinco milhões de acessos ${ }^{4}$.

O anúncio se organiza da seguinte forma: ao centro de um fundo cinza, uma lata de cerveja é vista do alto; nela está projetada a cena de uma ciclista que pedala num parque próximo do trânsito. Ouve-se, inclusive, o barulho relativo às pedaladas na bicicleta e ao

\footnotetext{
${ }^{4}$ Fonte: http://exame.abril.com.br/marketing/noticias/como-a-fiat-trabalha-inovacao-em-sua-estrategiade-marketing
} 
trânsito como buzinas, motores etc. A ciclista encontra-se pedalando especificamente na parte do lacre da latinha. Ao lado dessa cena aparece a frase: "Agora você vê". Em seguida, uma mão abre a lata de cerveja, rompendo o lacre, o que faz com que a ciclista desapareça da cena, dando lugar à espuma da cerveja que emerge da lata recém-aberta. Ao fundo, o barulho de uma latinha recém aberta se sobrepõe ao do trânsito e das pedaladas. Ao lado dessa cena aparece: “Agora não". Por fim, surge ao centro da tela o emblema da empresa e abaixo dele os dizeres: "Evite acidentes. Não beba e dirija". As imagens abaixo ilustram a sequência das cenas do anúncio.

Cena 01

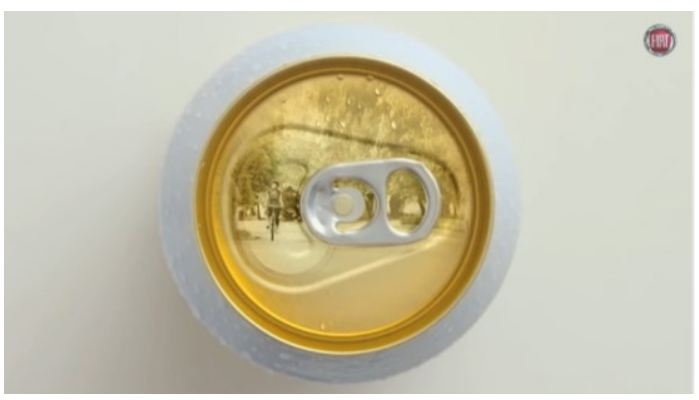

Cena 02

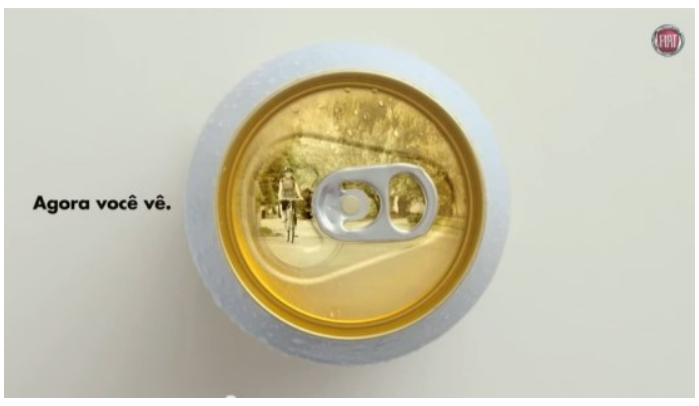

Cena 03

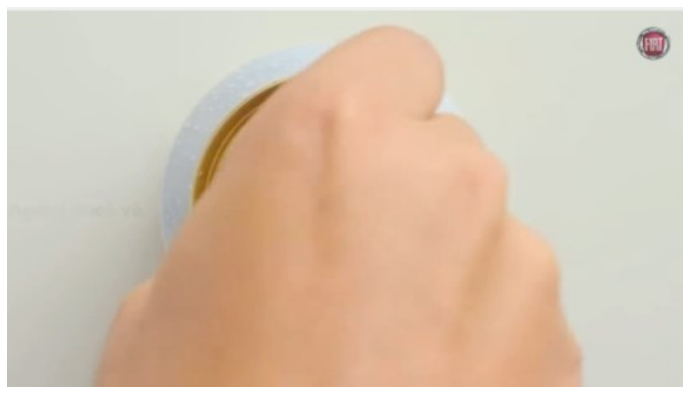




\section{Cena 04}

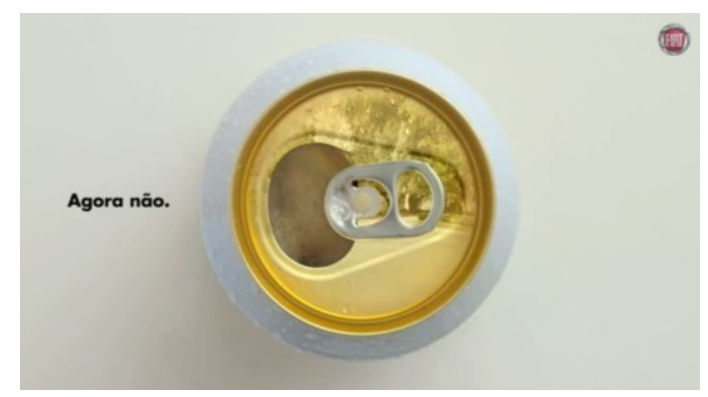

Cena 05

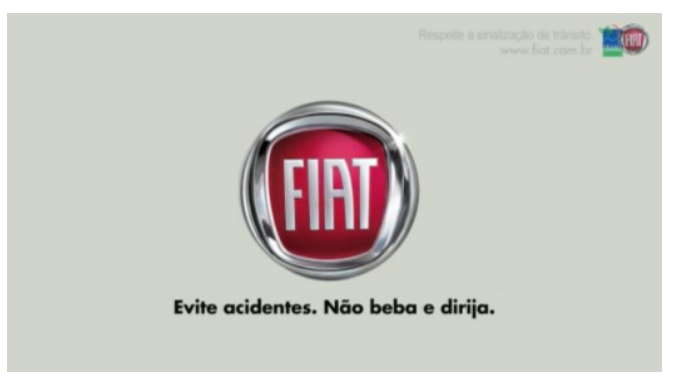

Numa perspectiva sociointeracionista, os gêneros textuais são produtos culturais situados em um determinado contexto sócio-histórico e engendrados a partir de determinadas práticas sociais. Enquanto fenômenos contextualmente situados, instituem-se mediante a interação. Nesse caso, o anúncio em questão situa-se num contexto em que é comum a prática de beber antes de dirigir (vide a frequência com que o enunciado "se beber, não dirija" se manifesta e se reproduz nos anúncios publicitários, com algumas variações possíveis, o que aponta para a existência de uma lei de regulamentação que prevê a responsabilização social das empresas que comercializam bebidas alcoólicas em demarcar sua posição a partir desta frase, como se a simples presença da frase "amenizasse" o que foi apresentado anteriormente positivamente em relação aos produtos comercializados).

Embora seja uma campanha de conscientização social, o anúncio é uma publicidade, sendo, portanto, uma prática social eminentemente persuasiva, cuja finalidade primeira é condicionar a "audiência" a uma ideologia específica, nesse caso o que se explicita é o convencimento de agir com maior responsabilidade no trânsito. Para tanto, o anúncio se estrutura de modo a indicar os efeitos nocivos da bebida na percepção do motorista. Isso é evidenciado pela sequência das cenas que articulam 
múltiplas linguagens (verbal, visual e sonora). Visual: a latinha de cerveja lacrada, que remete a não ingestão de álcool e aos efeitos benéficos dessa situação, ou seja, a percepção clara do que está ocorrendo - a ciclista pedalando à sua frente. Essa compreensão é construída pela articulação com a linguagem verbal - "Agora você vê" que confirma a clareza de percepção do motorista, aqui construído como o interlocutor do anúncio. O som ao fundo confirma ainda essa percepção clara, já que é possível distinguir pedaladas, buzinas, motores.

O rompimento do lacre e a mudança da cena, na qual a ciclista não mais aparece, remete à ingestão da bebida, que possui como implicação primeira essa alteração de percepção, ou seja, vê-se a cerveja e não mais a ciclista. Ao fazer essa leitura do anúncio, é possível perceber como a metonímia (abrir a cerveja como parte do ato completo de bebê-la), enquanto recurso linguístico, é utilizada para alcançar o efeito pretendido pelo autor do anúncio. É possível problematizar com os alunos aqui o fato de ser um recurso recorrente em textos do dia-a-dia, para além dos conhecidos exemplos de metonímia restritos à linguagem verbal. Na dimensão verbal, por sua vez, a sentença "Agora não", se relaciona à dimensão visual. Além disso, o som da cerveja ao se sobrepor ao do ambiente ratifica a percepção comprometida do possível motorista. Por fim, o surgimento da marca da empresa automobilística constrói para essa a imagem de promotora de boas atitudes no trânsito, contexto de seu interesse, uma vez que é ela quem produz os veículos usados como armas num contexto de direção perigosa, como é o da embriaguez. Assim, por meio de palavras, imagens, sons e mesmo silêncios (CARVALHO, 1996) constituem-se os sentidos do texto em questão.

Se analisássemos a dimensão verbal separadamente, possivelmente não chegaríamos à compreensão do texto. Por exemplo, na oração "Agora você vê", a compreensão do(s) sujeito(s) e objeto(s) do verbo "ver" só é recuperada pela dimensão não verbal. Nesse caso, "você” provável motorista (sujeito) e a ciclista (objeto). A própria referência do termo "você" exige tomar o texto para além de sua materialidade 'linguística', uma vez que o referido de "você” é o próprio interlocutor do anúncio. Além disso, o advérbio "agora" tomaria como referência temporal que tempo ou acontecimento? Sua compreensão só é recuperada pelos momentos expressos na narratividade do anúncio pela dimensão não verbal, ou seja, o "agora" se refere ao tempo específico dos acontecimentos: a ciclista pedalando e a não ingestão de bebida 
alcoólica e, posteriormente, a abertura da lata e provável ingestão da bebida e a não visão da ciclista. Nesse caso, a ingestão da bebida, ato representado metonimicamente pela abertura da lata, é que possibilita recuperar os sentidos do advérbio "agora" na compreensão desse texto, ou seja, é o ponto de referencia temporal.

Ao final do anúncio, na construção "Evite acidentes. Não beba e dirija" é o contexto do anúncio, sua articulação multimodal, que impossibilita a ambiguidade, por exemplo, da última frase, em que o termo coesivo "e", tipicamente classificado pela gramática tradicional como uma conjunção aditiva que une orações coordenadas, é compreendido de forma mais sofisticada, uma vez que a negação dessa frase se refere à sequência dos atos (beber seguido de dirigir) e não a cada um deles separadamente, o que possibilitaria a inversão das orações sem prejuízo do sentido (Não beba e dirija/Não dirija e beba), explicações típicas do ensino de conceitos da gramática tradicional para estruturas desse tipo.

Considerando que a publicidade tanto reflete quanto dita sistemas de valores que informam as práticas e os hábitos sociais, a leitura e análise de anúncios pode - e deve avançar para uma análise mais macro, social, no sentido de refletir com os alunos os efeitos nas práticas sociais para a empresa automobilística, por exemplo, de anúncios desse tipo, que são considerados publicidade indireta (GRACIOSO, 1995).

Nesse sentido, para uma formação crítica, é possível analisar como a organização desse anúncio e seu fechamento com o emblema da empresa incidem sobre a construção de uma identidade positiva para essa última, e problematizar como as estratégias de publicidade têm se constituído na modernidade tardia, ou seja, cada vez mais travestida de discurso "informativo", "socialmente engajado" (MARSHALL, 2003; SAMPAIO, 2003).

Fazendo isso, as aulas de Língua Portuguesa constituem-se como um momento privilegiado para que os alunos desenvolvam habilidades que os tornem cidadãos críticos e ativos em seu contexto sócio-histórico. Dessa forma, ainda, ao trabalhar com a publicidade, o professor de Língua Portuguesa contemplará a dimensão social de sua profissão no sentido de prover subsídios aos alunos para se posicionar de forma consciente em relação aos expedientes midiáticos com os quais convivem diariamente. Tais subsídios nascem da própria reflexão sobre a linguagem em uso, sobre sua materialidade, que é multimodal, atrelada às implicações sociais que desencadeia. 
O ambiente digital e mesmo televisivo, por exemplo, em que as dimensões vocovisual são o material de base, pode fornecer excelentes materiais para o trabalho com leitura crítica por meio da análise linguística. Pesquisas como a de Ferretti-Soares (2013) vêm nessa direção, de modo que têm mostrado como, linguisticamente, por meio da articulação verbo-voco-visual, empresas constroem uma identidade positiva de si em campanhas de publicidade indireta que utilizam o tema, por exemplo, de incentivo à pluralidade religiosa.

Cabe acentuar ainda que, ao considerar a relação entre a escola e o mundo destoante das práticas tradicionais de ensino, não se está considerando apenas o aluno na centralidade do processo, mas ambos, professor e aluno neste lugar, pois não se podem conceber os ambientes de ensino-aprendizagem sem a mediação do professor enquanto interlocutor mais experiente (ROSA, 2014). É preciso, pois, que a escola não negligencie a presença dos espaços de interação possíveis dentro e fora da sala de aula, engaiolando espaços em métodos tradicionais de ensino castradores da criatividade e da emancipação dos sujeitos frente à realidade histórica, social e cultural em que vivem.

\section{CONSIDERAÇÕES FINAIS}

Falar sobre a emergência de processos de ensino e aprendizagem que considerem a interação entre as linguagens em diferentes textos pressupõe que haja deslocamentos e reconfigurações no ensino para que este se afaste de uma concepção tradicional, sobretudo no que diz respeito ao encontro da escola com textos multimodais (re)produzidos através dos espaços virtuais e das mídias em geral. Dessa forma, está aqui está imbricada a discussão acerca da relação dos seres humanos com as novas tecnologias. Torna-se então necessário acrescentar que a tecnologia, sendo compreendida a partir da inscrição de movimentos humanos na história do mundo e de cada sujeito, não pode ser percebida como algo acabado, pronto ou isento de nuances, pois vai se modificando com o passar do tempo assim como mudam os modos que os sujeitos têm de se comunicar com o outro.

Nesse contexto, a publicidade foi se modificando gradativamente, somando modos de sofisticar o discurso persuasivo que a torna possível para constituir-se ideologicamente a partir desse discurso. Sendo assim, o multimodal está presente em 
textos publicitários na atualidade, fazendo com que, devido à exposição frequente em que estes emergem, possam ser trabalhados na escola e problematizados. Um dos êxitos significativos de perceber e considerar a existência do multimodal é o aparecimento de análises que compreendam instâncias discursivas, lexicais e que empreendam interpretações possíveis para além da análise do verbal somente, assim como análises que visem problematizar cada elemento verbal e não verbal como constituinte e passível de significação na relação com os outros elementos e com o todo.

Finalmente, para situar o papel da escola na atualidade, cabe direcionar nosso olhar para o educador e as instâncias de ensino e aprendizagem. Nesse contexto, o anúncio publicitário traz a característica de constituir-se em uma prática social eminentemente persuasiva, cuja finalidade primeira é condicionar a "audiência" a uma ideologia específica. Dessa forma, possibilitar que na sala de aula sejam criados espaços de reflexão acerca da multimodalidade de textos deste tipo, por exemplo, pode ampliar o escopo de problematizações empreendidas na escola.

\section{REFERÊNCIAS}

BAGNO, M. A norma oculta: língua \& poder na sociedade brasileira. São Paulo: Parábola Editorial, 2003.

BAKHTIN, M. (VOLOSHINOV, V. N). Estética da Criação Verbal. $4^{\text {a }}$ ed. São Paulo: Martins Fontes, 2003.

BAKTHIN, M. Marxismo e filosofia da linguagem. São Paulo: Huicitec, 2002.

BAKHTIN, M. O discurso no romance. In: BAKHTIN, M. Questões de literatura e estética. São Paulo: Huicitec, 1988.

BRASIL. SECRETARIA DE EDUCAÇÃO FUNDAMENTAL. Parâmetros Curriculares Nacionais: terceiro e quarto ciclos do ensino fundamental: língua portuguesa. Brasília: MEC/SEF, 1998.

BRITTO, L. P. L. A sombra do caos: ensino de línguas x tradição gramatical. Campinas: Mercado da Letras, 1997.

CARVALHO, N. de. Marketing e publicidade: mídia impressa e virtual, usos na sala de aula. Anais do $2^{\circ}$ Simpósio Hipertexto e Tecnologias na Educação, multimodalidade e ensino. Pernambuco: UFPE, 17 a 19 de setembro de 2008. 
Disponível em: http://www.ufpe.br/nehte/simposio2008/ anais/Nelly-Carvalho.pdf. Acesso em 02/12/2014.

CARVAlHO, N. de. Publicidade: A linguagem da sedução. São Paulo: ática, 1996.

CHARAUDEAU, P. De la competencia social de comunicación a las competencias discursivas. Revista Latinoamericana de Estúdios Del Discurso, 1 (1), p. 7-22, 2001.

DESCARDECI, M. A. A. de S. Ler o mundo: um olhar através da semiótica social. ETD - Educação Temática Digital, Campinas, 3 (2), p.19-26, 2002.

DIONISIO, A. P. A multimodalidade discursiva na atividade oral e escrita. In: MARCUSCHI, L. A.; DIONISIO, A. P. (orgs). Fala e Escrita. Belo Horizonte: Autêntica, p. 177-196, 2005.

DIONÍSIO, A. P. Gêneros multimodais e multiletramento. In: KARWOSKI, A. M.; GAYDECZKA, B.; SIEBENEICHER, K. (Orgs.) Gêneros textuais: reflexões e ensino. Rio de Janeiro: Lucerna, p. 131-144, 2006.

FERRETTI-SOARES, V. A. S. A série televisiva O Sagrado e a prática de publicidade institucional indireta da Rede Globo: uma análise crítica de gênero. Dissertação (Mestrado em Linguística) - Universidade Federal de Santa Catarina, Florianópolis, 2013.

FREIRE, P. Pedagogia da Autonomia: Saberes necessários à prática educativa. São Paulo: Paz e Terra, 1997.

FREIRE, P. Educação como prática de liberdade. $32^{\mathrm{a}}$ ed. Rio de Janeiro: Paz e Terra, 2009.

GERALDI, J. W. Portos de passagem. São Paulo: Martins Fontes, 1997.

GRACIOSO, F. Propaganda institucional: nova arma estratégica da empresa. São Paulo: Atlas, 1995.

KOCK, I. V. Interação pela linguagem. São Paulo: Contexto, 2003.

KRESS, G.; LEEUWEN, T. V. Multimodal discourse: the modes and media of contemporary communication. New York: Oxford University, 2001.

KRESS, G.; LEEUWEN, T. V. (1996). Reading Images: the grammar of visual design. London: Routledge, 1996.

LOPES-ROSSI, M. A. G. Leitura de Propaganda Impressa. Anais do 6º . Seminário de Pesquisas em Lingüística Aplicada (SePLA), Taubaté. ISSN: 1982-8071, CD-Rom, s.p., 2010. 
MARCUSCHI, L. A. Gêneros textuais: definição e funcionalidade. In: DIONISIO, A. P.; MACHADO, A. R.; BEZERRA, M. A. (orgs). Gêneros Textuais \& Ensino. Rio de Janeiro: Lucerna, p. 19-36, 2002.

MARSHALL, L. O jornalismo na era da publicidade. São Paulo: Summus, 2003.

MAYER, R. Multimedia Learning. Cambridge: Cambridge University Press, 2001.

ROJO, R. Letramentos múltiplos: escola e inclusão social. São Paulo: Parábola, 2009.

ROSA, S. S. da. Pinóquio educador: ensinar e aprender na escola contemporânea. São Paulo, Cortez, 2014.

SAMPAIO, R. Propaganda de A a Z. Rio de Janeiro: Elsevier, 2003.

SILVEIRA, E. L. Agir na urgência e decidir na incerteza: sobre a sociedade multimodal e a formação de professores. Revista Eletrônica Interdisciplinar. 1, (11), p. 19-23, 2014.

\section{OS AUTORES:}

Raimundo Expedito dos Santos Sousa é doutorando em Estudos Literários pela Universidade Federal de Minas Gerais - UFMG; Bolsista da Fundação de Amparo à Pesquisa do Estado de Minas Gerais - FAPEMIG; Mestre em Letras pela Universidade Federal de São João del-Rey - UFSJ.

E-mail: raimundo_sousa@terra.com.br

Vanessa Arlésia de Souza Ferretti-Soares é Doutoranda e Mestre em Linguística Aplicada pelo Programa de Pós-Graduação em Linguística da Universidade Federal de Santa Catarina - UFSC; Bolsista da Coordenação de Aperfeiçoamento de Pessoal de Nível Superior - CAPES.

E-mail: vanessa.arlesia@gmail.com

Ederson Luís Silveira é Mestrando em Linguística pela Universidade Federal de Santa Catarina - UFSC; Bolsista da Coordenação de Aperfeiçoamento de Pessoal de Nível Superior - CAPES; Pós-graduando em Ontologia e Epistemologia pela AVM Faculdades Associadas; membro do Grupo de Estudos em Territorialidades da Infância e Formação Docente (GESTAR/CNPq).

E-mail: ediliteratus@gmail.com 